In search of inclusion: informal sector participation in a voluntary, defined contribution pension system

Renuka Sane and Susan Thomas

Indira Gandhi Institute of Development Research, Mumbai October 2013

http://www.igidr.ac.in/pdf/publication/WP-2013-022.pdf 


\title{
In search of inclusion: informal sector participation in a voluntary, defined contribution pension system
}

\author{
Renuka Sane and Susan Thomas \\ Indira Gandhi Institute of Development Research (IGIDR) \\ General Arun Kumar Vaidya Marg \\ Goregaon (E), Mumbai- 400065, INDIA

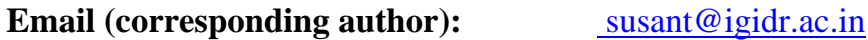

\begin{abstract}
This paper examines who contributes and who persists in contributing in a national, voluntary, defined contributory pension program, where the government provides the incentive of matching contributions of a minimum amount (USD 16). The paper uses proprietary data from a financial services firm where 12 percent of customers (37000 individuals) chose to participate in this program. The evidence shows that only about 50 percent of contributors reach the minimum amount for the co-contribution, but that participants persist in contributing even if they failed to contribute the minimum amount in a given year. While this paper does not provide causal estimates, it does present evidence of considerable interest among the informal sector in a state-run voluntary pension program in an emerging market where access to formal finance is otherwise poor.
\end{abstract}

Keywords: informal sector workers; pension accounts; matched defined contribution;

JEL Code: H55; G11; D14;

\section{Acknowledgements:}

Renuka Sane is with the Indian Statistical Institute, Delhi. Susan Thomas is at the Finance Research Group, IGIDR, Mumbai. Email: renuka@saner.org.in, susant@igidr.ac.in, URL: http://www.ifrogs.org.We thank Robert Palacios and Ajay Shah for useful discussions. The paper also benefitted from comments at the Workshop on Emerging Economies at the University of New South Wales, Australia. We especially thank the staff of Kshetriya Grameen Financial Services (KGFS) for insightful discussions and access to data. Arko Bhattacharya and Parthasarathi Edupally provided excellent research assistance 


\title{
In search of inclusion: informal sector participation in a voluntary, defined contribution pension system
}

\author{
Renuka Sane Susan Thomas*
}

October 21, 2013

\begin{abstract}
This paper examines who contributes and who persists in contributing in a national, voluntary, defined contributory pension program, where the government provides the incentive of matching contributions of a minimum amount (USD 16). The paper uses proprietary data from a financial services firm where 12 percent of customers (37000 individuals) chose to participate in this program. The evidence shows that only about 50 percent of contributors reach the minimum amount for the co-contribution, but that participants persist in contributing even if they failed to contribute the minimum amount in a given year. While this paper does not provide causal estimates, it does present evidence of considerable interest among the informal sector in a state-run voluntary pension program in a emerging market where access to formal finance is otherwise poor.
\end{abstract}

${ }^{*}$ Renuka Sane is with the Indian Statistical Institute, Delhi. Susan Thomas is at the Finance Research Group, IGIDR, Mumbai. Email: renuka@saner.org.in, susant@igidr.ac.in, URL: http://www.ifrogs.org. We thank Robert Palacios and Ajay Shah for useful discussions. The paper also benefitted from comments at the Workshop on Emerging Economies at the University of New South Wales, Australia. We especially thank the staff of Kshetriya Grameen Financial Services (KGFS) for insightful discussions and access to data. Arko Bhattacharya and Parthasarathi Edupally provided excellent research assistance. 


\section{Contents}

\begin{tabular}{lll}
\hline 1 & Introduction & 3
\end{tabular}

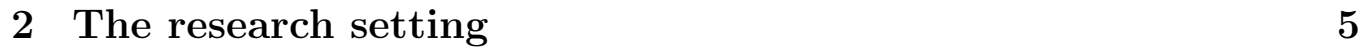

$2.1 \quad$ NPS-Swavalamaban (NPS-S) . . . . . . . . . . . . . . . . 6

$2.2 \quad$ A distributor of NPS-S, KGFS . . . . . . . . . . . . . . . . 7

\begin{tabular}{lll}
\hline 3 & Hypothesis & 8
\end{tabular}

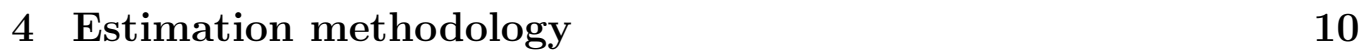

$\begin{array}{lll}5 & \text { Describing the data } & 11\end{array}$

$5.1 \quad$ Who participates and persists? . . . . . . . . . . . . . 13

5.2 Time dynamics of NPS-S participation . . . . . . . . . . . . . 17

5.2 .1 The role of distributors . . . . . . . . . . . . . . . . . 19

$\begin{array}{llr}6 & \text { Results } & 20\end{array}$

6.1 Participation decision . . . . . . . . . . . . . . . . . 20

6.2 Contributions persistence . . . . . . . . . . . . . . . . 23

\begin{tabular}{lll}
\hline 7 & Conclusion & 26
\end{tabular} 


\section{Introduction}

Increasing pension coverage is an important goal of pension reform in lowincome countries (ILO, 2010). Since universal transfer programs are often not fiscally sustainable, and mandating contributions is not administratively viable, policy has focussed on facilitating the build up of voluntary savings. In recent years, several emerging economies including China, Dominican Republic, India, Indonesia, Vietnam, have begun experimenting with some form of matched defined contribution (MDC) pension programs where the government provides an incentive by matching voluntary contributions made by plan members (Palacios and Robalino, 2009).

However, unlike high income economies where there is a positive impact of MDC programs, less is established about the success of such programs in low-income economies. A build up of voluntary savings face two difficulties in the latter. One is the large presence of the informal sector. The wellknown policy instruments of employer-based programs and tax-breaks for pension contributions are ineffective for those who are employed outside the formal sector. Second, if large parts of the economy are excluded from formal finance, it is difficult to provide information and infrastructure that can integrate modern fund management with the small value contributions expected from informal sector workers at sufficiently low transactions costs. The optimal combination of incentives and infrastructure in such an environment remains a challenge.

This paper uses observations about informal sector participation in a national MDC program in India to ask the following questions: Do informal sector workers volunteer to participate in a contributory pension program? Do they persist in making contributions? What can be infered about the scope of voluntary contributory programs?

The setting is the NPS-Swavalamban (NPS-S) scheme introduced by the Pension Fund Regulatory Development Authority in India, in April 2010. In the NPS-S, those in the informal sector can invest amounts as low as Rs.100 (US\$2) to their individual accounts through a network of entities, called aggregators licensed to undertake outreach, marketing and enrollment functions. To incentivise a minimum yearly contribution, the government agreed to gift Rs.1000 (US\$17) to those accounts that had managed to contribute Rs.1000 or more before the end of each financial year, for the first three years i.e. till March 2014. The scheme was recently extended to 2016-17. 
This paper is one of the first attempt: ${ }^{1}$ at understanding the determinants of voluntary pension participation and persistence of contributions in the context of low income households in the informal sector with limited access to both formal finance and social security benefits.

In the aggregate, about a million individuals signed up for the NPS-S $\left.\right|^{2}$ This paper analyses the participation in the NPS-S of the customers of a single service provider called the Kshetriya Grameen Financial Services (KGFS). The KGFS chooses to provide financial services in localities where other formal financial institutions do not operate, with operations in five districts across three states in India during the period of November 2010 to March 2013.

We find that among the KGFS customer base, around 12 percent, or 37569 individuals, chose to enroll in the NPS-S pensions program. Of these, about 50 percent contributed Rs.1000 in at least one financial year. The KGFS customers who participate in the NPS-S program are among the poorer of the total customer base. They tend to have less accumulated wealth and are households in the lower income categories in the data. They are also among the less educated and tend to have poorer socio-economic indicators (such as access to cooking gas and private sanitation) compared to average customer in the sample.

What is unique in that repeated observations of the same customers across different years allows us to analyse the persistence of contributions in this dataset. This is a new perspective on informal sector into a voluntary pension schemes, where the persistence is not guaranteed through employer interactions. We find that those who choose to participate in the NPS-S persist in their contributions. This is irrespective of whether they are able to reach the minimum amount required for the MDC. Thus, the evidence suggests that the MDC is not a key factor for participation into such voluntary DC pension programs. Further, since the KGFS specifically chooses to operate in areas where households have little or no access to formal finance, it is likely that the choices of these customers reflect the behaviour of households who have little access to formal finance.

The NPS-S is a relatively young program, and more experience has to build up before we are able to measure the full impact of this scheme. The results in this paper, while localised to a single distributor, do provide evidence

\footnotetext{
${ }^{1}$ Palacios and Sane $(2013)$ provide preliminary results on NPS-S participation based on a subset of the data presented in the paper. They, however, do not discuss persistence of contributions.

2 http://financialservices.gov.in/pensionreforms/PRstatistics.asp
} 
that low-income, informal sector workers are interested in illiquid pension accounts.

The paper proceeds as follows. We begin with a description of the research setting, including institutional details about the scheme and the intermediary in section 2. The main hypotheses are discussed in in section 3 . Section 4 describes the empirical methodology, and section 5 the data. Results are presented in section 6. Section 7 concludes.

\section{The research setting}

Most prior research on pension participation has centered around pension programs associated with the employer 3 The focus of this research has been on individual as well as employer characteristics that determine participation and contributions. The general consensus is that participation and contributions are positively related to age, income, education and job tenure and negatively related to the presence and generosity of a defined benefit plan. Plan characteristics such as the presence of a matching contribution by employers, quality of informational material are also found to be important determinants of participation and contributions (Papke, 1995, Bernheim and Garrett, 1996; Bassett, Fleming, and Rodrigues, 1998; Guariglia and Markose, 2000; Munnell, Sunden, and Taylor, 2002).

Recent work has emphasised the causal role of plan design, and the value of matched contributions on pension participation and has also begun to examine the role of trust on 401(k) savings behavior (Choi, Laibson, and Madrian, 2004; Huberman, Iyengar, and Jiang, 2007; Engelhardt and Kumar, 2007: Saez, 2009; Madrian, 2012; Agnew et. al, 2012)

Little is known about the experience in a setting where participation is not routed through the employer, is voluntary, and is made in the absence of other state funded pension welfare programs. There is, in fact, skepticism about the ability of poor people to meaningfully participate in voluntary contributory pension schemes (Holzmann, Packard, and Cuesta, 2000). Participation of this category of households in insurance programs, which provide cover against more immediate risks, also leaves little reason to be optimistic about the success of a pension scheme, at least in the short run Giné, Townsend, and Vickery, 2008; Cole et. al., 2012).

\footnotetext{
${ }^{3}$ Examples include 401(k) plans in the US, or the Superannuation Guarantee in Australia, the National Pension Saving Scheme in the UK, KiwiSaver in New Zealand.
} 
In the context of low-income households in the U.S., Beverly and Sherraden (1999) point out that such households often do not have access to institutionalised saving mechanisms that involve explicit rules, incentives and subsidies, all of which significantly influence saving rates and asset accumulation. More recent work in the context of health saving accounts in Kenya shows that devices which simply provide poor households with a safe place to keep money increased savings by a substantial amount (Dupas and Robinson, 2012). Household survey results from India suggest that a significant proportion of individuals in the informal sector, one in four paid workers, are interested in such a DC pension scheme (IIMS Dataworks, 2008). The question on the scope of voluntary pension programs thus does not appear to be settled and does not have an obvious answer. The analysis in this paper contributes specifically to the limited literature on the scope of voluntary contributory pension programs for informal sector workers.

\section{$2.1 \quad$ NPS-Swavalamaban (NPS-S)}

One of the aspects of reforms in the Indian financial sector in 1998 was the effort to improve old age income security in India by putting in place the National Pension Scheme (NPS). The NPS is a defined contribution individual account system with full portability across jobs and locations. It follows an unbundled architecture where the process of selling, record-keeping and fund management are managed by different entities for reasons of administrative and cost efficiency. Contributions of government employees are routed through the Central Record-keeping Agency (CRA) to the various fund managers licensed by the Pension Fund Regulatory Development Authority (PFRDA). The NPS annual fund management charge of 0.0009 per cent is extremely low by world standards.4

The NPS was made mandatory for government employees in January 2004, replacing the old defined benefit pension system. Since then, the NPS has also been made available to citizens of India on a voluntary basis. One variant of the NPS for workers in the unorganised sector is called the NPS Swavalamban or NPS-S scheme. The NPS-S launched in April 2010 is a co-contribution scheme designed for citizens in the unorganised sector. 5 It is important to bear in mind that the scheme functions in an environment

\footnotetext{
${ }^{4}$ For a description and a historical treatment of the NPS, see Sane and Shah (2011); Shah (2006); Dave (2006).

${ }^{5} \mathrm{An}$ individual is in the unorganised sector if (s)he is not salaried and does not have a provident fund contribution.
} 
where there is minimal social security available to its target population ${ }^{6}$

In the scheme, the government promises to contribute Rs.1,000 (under U.S. $\$ 17$ ) into the individual account for every Rs.1,000 contributed, upto a limit of Rs.12,000 per year. The Rs.1000 threshold was designed as a minimum amount required to accumulate enough to buy a modest annuity at retirement. The co-contributions were initially designed to continue until March 2014, and were recently extended to continue till 2016-17.7 An annual flat fee of Rs.70 is deducted from the invested amount, while each transaction is charged at Rs.5 per transaction after the first twelve contributions which are free.

At the time of retirement, 8 the account holder will be required to annuitise 40 percent of accumulated pension wealth. If the holder chooses to withdraw before the retirement age, 80 percent annuitisation is mandatory subject to the overriding condition that the annuity yields a minimum amount of Rs.1,000 per month. $9^{9}$

$\mathrm{Hu}$ and Stewart (2009) claim that for a contributory program to work in lowincome settings, it must have the following characteristics: It must be flexible in its terms for the amount, and periodicity of contributions, it must provide monetary incentives to participate, and it must be accompanied by financial education. The NPS-S, with its network of aggregators, matching contribution, and flexible contribution terms comes close to the ideal experiment to understand the scope for voluntary pensions.

\subsection{A distributor of NPS-S, KGFS}

In late 2010, the PFRDA established incentives to encourage the introduction of entities that would serve as account aggregators to extend the coverage of the system. These aggregators were mostly NGOs, or non-banking finance companies (NBFCs) that met a predefined set of criteria that would qualify them to undertake outreach, marketing and enrollment functions.

\footnotetext{
${ }^{6}$ For example, the only benefit for destitute elderly in India is The Indira Gandhi National Old Age Pension Scheme (IGNOAPS), run by the Ministry of Rural Development provides a pension of Rs.200 (US\$ 4) per month to those below the poverty line. State governments are encouraged to also provide an equal amount, bringing the total pension to at least Rs.400 (US\$ 8).

7 http://financialservices.gov.in/pensionreforms/PR_newinitiatives.asp

${ }^{8}$ In India, the retirement age is set at 50.

${ }^{9}$ This minimum pension ceiling may be revised from time to time.
} 


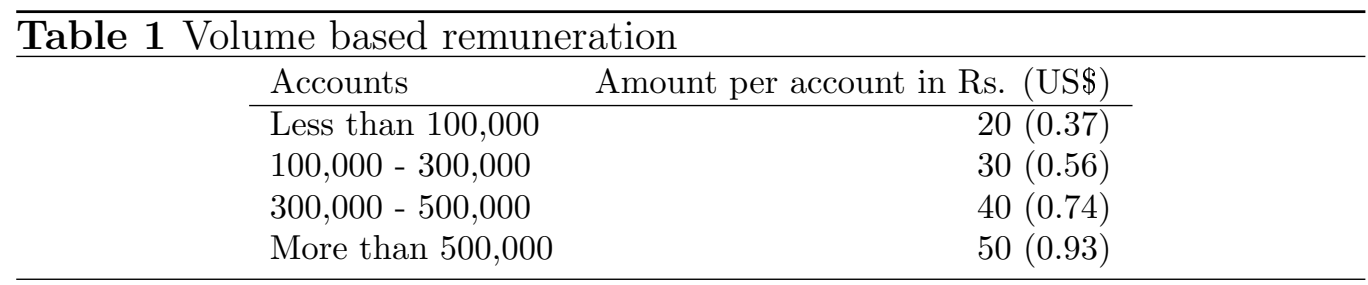

The Kshetriya Grameen Financial Services (KGFS) is one such aggregator. As of March 2013, KGFS operated out of five geographical regions:

- Two districts in the state of Tamil Nadu in South India, which are fertile agrarian economies.

- Two districts in the Eastern Indian state of Orissa, which are characterised by subsistence agriculture supplemented by domestic migration.

- Five hill districts in the state of Uttarakhand in North India that are sparsely populated and are dominated by trade and services.

These regions are particularly chosen because of their inaccessibility to formal finance. In each village that KGFS operates, a bank branch is at least 2-5 kms away. This implies that most individuals in KGFS villages have had limited access to formal finance, and almost certainly no access to pension products.

As an NPS-S aggregator, KGFS is paid Rs.100 (about US\$2 dollar) per enrollment by the Pension Fund Regulatory Development Authority (PFRDA) since April 2011. For the first year i.e. 2010, this was Rs.50 per enrollment. In addition, there is a volume based payment described in Table 1. This is payable only if the customer has contributed a minimum of Rs.1,000 towards the pension account. The remuneration pattern thus incentivises sign-up of participants as much as it does subsequent contributions.

In the financial year 2012-13, the management of KGFS took a decision to change its distribution strategy from focusing on the matched contribution feature of the NPS-S, to emphasizing the importance of long-term savings. This was done to ensure that customers had understood the long-term nature of the pension contract, and had enrolled for the right reasons. 


\section{Hypothesis}

According to traditional neo-classical theory, long-term income is the primary determinant of consumption and consequently saving. Higher income households save a larger portion of their incomes, and accumulate greater wealth, than lower-income households (Hubbard, Skinner, and Zeldes, 1994; Dynan et. al., 2004). This leads to the first hypothesis about participation in the NPS-S

Hypothesis 1: Pension participation and persistence increases with income.

Another hypothesis centers around the role of pensions as part of a household portfolio. In the absence of long-term savings avenues, a household may develop a portfolio of substitute assets. Land and home-ownership may be seen as wealth to be drawn-down for consumption in old age. International evidence on draw-down of home-equity is weak (Poterba et. al., 2011; Angelini et. al. 2012), and in the absence of financial instruments like reverse mortgages, even less likely to materialise. However, land and the family home may have an important role to play in bequests (Angelini, 2007), and may therefore have a larger role as a substitute for pension wealth.

Hypothesis 2: Both pension participation and persistence decreases with non-financial wealth.

In traditional societies, children and especially sons often count as assets, and are expected to provide for old-age. Ebenstein and Leung (2010) find that in rural China, parents without sons are more likely to participate in voluntary old-age programs than those with sons, and are more likely to have built up savings specifically intended for old age.

Hypothesis 3: Individuals with children, and especially male children will be less likely to participate.

In the NPS-S setting, the contribution amount of Rs.1000 is an important threshold for availing the matched benefit. This may be achieved either by one large valued transaction or multiple smaller valued transactions. In fact, the appeal of the NPS-S is that it allows for multiple low-value transactions thereby making it possible to solve the transactions costs problem in providing informal sector pensions (MacKellar, 2009).

Hypothesis 4 Persistence should not depend on the value of the first contribution. 
Though these hypotheses are general and based on received wisdom from the economics literature, they help in anchoring expectations about the scope and success of a voluntary pension program for informal sector workers.

\section{Estimation methodology}

The goal of the empirical analysis is to estimate the determinants of voluntary pension participation and persistence. Towards this end, we first estimate a reduced form logit regression model of participation as follows:

$$
y_{i}^{*}=\alpha+x_{i} \beta+u_{i}
$$

where $y^{*}$ denotes the unobservable propensity to participate in the NPS-S. An individual is observed to enroll when $y_{i} * \geq 0$. The dependent variable is 1 if the individual opens an NPS-S account. $x$ is a vector of observable characteristics that affect $y^{*}$ such as income, financial assets and number of children. The model also controls for various demographic characteristics such as age, gender, education, occupation, religion and caste all of which are expected to influence an individuals participation probability. $\beta$ is a vector of coefficients.

When analysing the persistence of contributions in the NPS-S scheme, three measures lead to three different estimations as follows:

1. Total contributions adjusted for the number of months since enrollment.

We estimate the determinants of high contributions as follows:

$$
y_{i}=\alpha+x_{i} \beta+\epsilon
$$

where $y_{i}$ denotes the total contributions in an individual account, scaled by the number of months the account has been in existence. $x_{i}$ reflect the observable individual characteristics that are possible factors that influence the total contributions as per the hypotheses in Section 3.

2. Total contributions of Rs.1000 in every year since enrollment.

We analyse the characteristics of people who availed of the matched benefit from the government, using the following logit model:

$$
y_{i}^{*}=\alpha+x_{i} \beta+u_{i}
$$

where $y^{*}$ denotes the unobservable propensity to contribute Rs.1000 in each financial year. An individual is observed to contribute Rs.1000 
when $y_{i} * \geq 0$. The dependent variable is thus coded as 1 if the member has Rs.1000 in her account in each year since enrollment. $x$ is a vector of observable characteristics that affect $y^{*}$.

3. Probability of a second contribution.

Second contribution provides an understanding of who came back to contribute a second time, regardless of the total contributions accumulated. The probability of a second contribution, is estimated using a discrete hazard model described by (Allison, 1982) as follows:

$$
\ln \left(\frac{P_{t}}{1-P_{t}}\right)=\alpha_{t}+\beta_{k} X_{k}+\epsilon
$$

Here, the dependent variable is the conditional probability that an event will occur at time $t$, provided the respondent is at risk for the event at time $t-1$. The event in our model is the second contribution. Thus, $P_{t}$ is the probability that a member makes a second contribution at time $t$, given that she has not made a contribution at time $t-1$. $\alpha_{t}$ represents the baseline hazard function. We chose a non-parametric baseline, and create a duration-interval-specific dummy variable: one for each spell month at risk. $X$ represents a vector of observables.

The analysis is carried out at the frequency of a month. If the member contributes in a month, the dependent variable is coded as 1 , and 0 if there is no contribution. In the latter case, the respondent is still at risk during the following month, and is included in the next set of person-year observations. This implies that those members who never contribute a second time will be counted multiple times: once for each month that they are in the system.

\section{Describing the data}

The analysis in this paper is carried out on a proprietary database about individual participation of KGFS customers. What is unique about this dataset is that, in addition to the pensions contributions of these customers, the KGFS database contains rich observations about not just the individual but also their households, and for customers that sign up for the NPS-S as well as those that do not. This is because of the process through which KGFS enrolls a customer. Every potential customer is first enrolled into the KGFS system, when information on demographics, income and financial goals of the 
Figure 1 Distribution of total contributions.

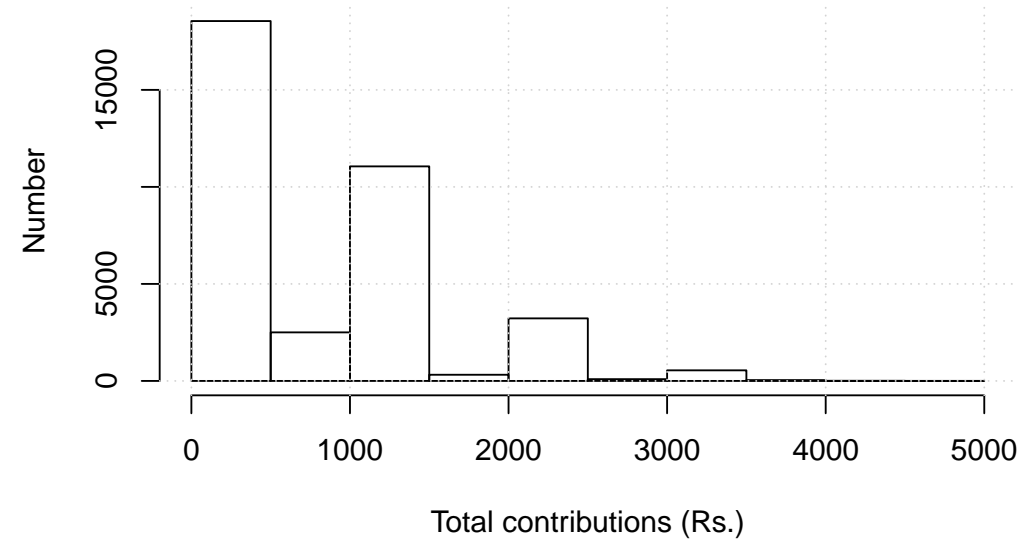

individual is recorded ${ }^{10}$ The individual then choose to buy one or more of the several products that KGFS offers. These include loans (joint-liability loans, emergency loans and gold loans), savings products (money-market mutual funds), insurance (personal accident insurance, term life insurance, livestock insurance) 11 Individuals often choose to not buy any of the products at the time of enrollment and instead sign up for the product at a later stage. This offers a unique opportunity to study the choices of individuals and link it back to their characteristics.

In this database, we observe that the participation rate of NPS-S is 12 percent of all the KGFS customers, which covers 37569 customers in March 2013. Figure 1 presents the total contributions made by members ${ }^{12}$ There is a hump at the Rs.1000 contribution, consistent with the matched contribution limit of the same amount. There is a large number of households with contributions below Rs.1000. Almost 49.81 percent of members have not managed to accumulate upto the minimum contribution limit at the end of March 2013. These individuals will not be able to avail the matched benefit and may also lose the Rs.70 account servicing fee. For these participants, enrolling in the pension scheme has probably not been a beneficial decision.

\footnotetext{
${ }^{10} \mathrm{KGFS}$ is in the process of implementing an algorithm that presents each individual with the optimal asset allocation to meet the stated goals.

${ }^{11}$ Ananth, Chen, and Rasmussen (2012) describe the KGFS operating model in detail.

12 The figure is truncated at Rs.5000, as a total of 15 households had contributed more than Rs.5000. The maximum contribution is Rs.15,200.
} 
We then focus on the probability of members coming back to contribute multiple times. Figure 2 presents the Kaplan-Meier survival curves of NPS-S participants. The event is a contribution, and the survival probabilities reflect the probability of not contributing a second (or third) time, conditional on having made the first (second) contribution.

The survival probability falls over the first twelve months, drops from about 0.7 to 0.65 between months ten and twelve and then plateaus after the fifteenth month. This implies that if a member does not contribute within twelve to fifteen months of making the previous contribution, she is unlikely to do so after.

The survival probability of the third contribution, conditional on the second is lower than that of the second contribution, conditional on the first. This probably reflects that the pool of people who make a second contribution are more serious about their pension accounts, and more likely to persist going forward. The drop in survival probability between months ten and twelve is also sharper, from 0.6 to almost 0.4 , suggesting that this pool of members are more likely to continue to persist.

We turn next to understanding the characteristics of households who participate and persist.

\subsection{Who participates and persists?}

Table 2 presents the characteristics of KGFS customers that are observed the first time the member interfaces with KGFS 13 The customers includes those who are NPS-S participants, as well as those who are not.

NPS-S members appear to be poorer and less educated compared to the KGFS universe. The median annual household income per capita of NPS-S participants is Rs.24750, lower than that of the full sample at Rs.26000. 1.9 percent are graduates while 77.3 percent have studied upto class 12 .

They also fare poorly on socio-economic indicators such as access to cooking gas and private sanitation. 19.2 percent of NPS-S members have private toilets, as opposed to 25.5 percent of the full sample. 14 percent of the members use cooking gas, as opposed to 17 percent of the full sample.

\footnotetext{
${ }^{13}$ These characteristics may change over time. However, some of the changes may be a result of participation. We have therefore chosen to report the first observed characteristic to avoid the complications of reverse causality.
} 
Figure 2 Kaplan-Meier estimates for NPS-S participants

This figure presents the Kaplan-Meier survival curves of NPS-S participants. The event is defined as making a contribution. The top panel reflects the probability of not contributing a second time conditional on having made the first contribution. The bottom panel reflects the probability of not contributing for the third time conditional on having made the second contribution). The probability of not contributing twelve months after making the first contribution is about 0.6 , reflecting the low persistence of the sample.

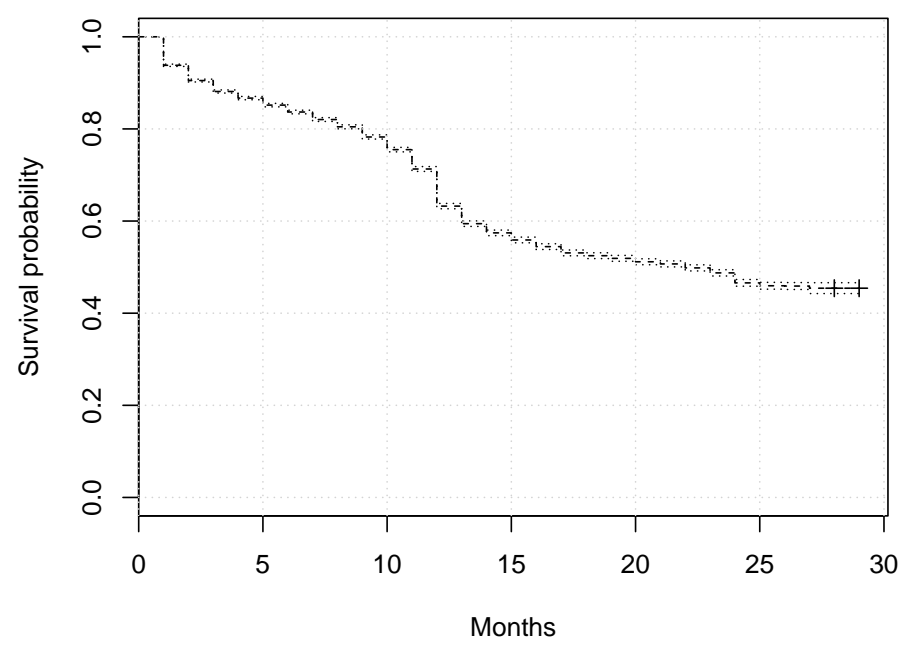

(a) $\operatorname{Pr}(2 \mathrm{nd}$ contribution, conditional on 1st)

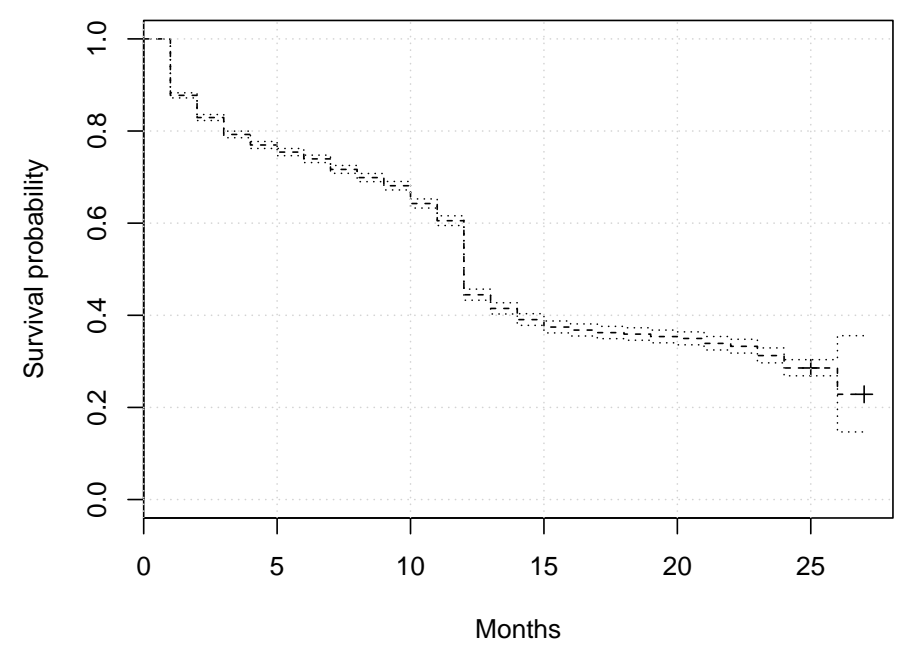

(b) $\operatorname{Pr}(3 \mathrm{rd}$ contribution, conditional on 2nd) 


\section{Table 2 Who participates?}

The table describes the summary statistics of NPS-S members and the full sample. The numbers are percentages, unless stated otherwise.

For example, 82 percent of the NPS-S members and 50 percent of the full sample is female. The table restricts the sample to those below the age of 75 . House type refers to the quality of the house. Education refers to the highest education among all members of the household. Caste reflects the non SC/ST categories.

\begin{tabular}{|c|c|c|}
\hline & NPS-S & Full sample \\
\hline Number & 37608.0 & 302398.0 \\
\hline Female & 82.2 & 50.2 \\
\hline Edu: Class 12 & 77.3 & 77.1 \\
\hline Edu: Graduate & 1.9 & 3.6 \\
\hline Edu: Illiterate & 20.8 & 19.3 \\
\hline Occ: Agriculture & 16.3 & 19.8 \\
\hline Occ: Business & 10.2 & 11.1 \\
\hline Occ: Driver & 0.8 & 1.4 \\
\hline Occ: House-wife & 15.6 & 8.8 \\
\hline Occ: Labour & 53.8 & 50.7 \\
\hline Occ: Not working & 0.5 & 2.9 \\
\hline Occ: Rental income & 0.0 & 0.0 \\
\hline Occ: Salaried & 2.7 & 5.1 \\
\hline Married & 97.8 & 87.3 \\
\hline Age (median) & 38.0 & 38.0 \\
\hline HH per capita income (median, Rs. thousand) & 24.8 & 26.0 \\
\hline Owns land & 36.6 & 41.7 \\
\hline Owns house & 85.8 & 84.7 \\
\hline House type: high & 25.9 & 31.8 \\
\hline House type: medium & 6.1 & 8.4 \\
\hline House type: low & 68.0 & 59.8 \\
\hline No. of children (median) & 2.0 & 2.0 \\
\hline No. of consumer durables (median) & 2.0 & 2.0 \\
\hline Have access to health care & 37.8 & 38.6 \\
\hline Have electricity & 86.5 & 86.3 \\
\hline Have private toilet & 19.2 & 25.5 \\
\hline Cooking medium: Gas & 14.0 & 16.7 \\
\hline Religion: Hindu & 94.8 & 94.6 \\
\hline Caste: Non OBC/SC/ST & 10.7 & 18.8 \\
\hline
\end{tabular}




\section{Table 3 Who persists?}

This table reflects the characteristics of households by persistence categories. Category I consists of those households who have contributed more than Rs.1000 in each financial year since enrollment. Category II consists of households that have managed to contribute Rs.1000 at least once since enrollment, but have not managed to do it for all the years. Category III is households who have not contributed Rs.1000 or more in any financial year since enrollment. The numbers are percentages, unless stated otherwise.

\begin{tabular}{lrrr} 
& \multicolumn{3}{c}{ Category } \\
& I & II & III \\
\hline Number & 11471.0 & 5477.0 & 19406.0 \\
Male & 11.4 & 6.8 & 25.4 \\
Own land & 27.8 & 28.2 & 29.1 \\
Own home & 69.5 & 74.1 & 63.2 \\
Have electricity & 88.9 & 90.7 & 84.1 \\
Private toilet & 20.6 & 16.0 & 19.6 \\
Cooking medium: Gas & 15.4 & 11.4 & 14.4 \\
Caste: Non OBC/ST/SC & 91.0 & 95.8 & 86.1 \\
Median household income (Rs.) & 27616.7 & 26800.0 & 25000.0 \\
Number of children & 2.0 & 2.0 & 2.0
\end{tabular}

There are more lower-caste households in the NPS-S sample than in the entire KGFS data-base. Even though, there are an equal number of men and women in the KGFS data-base, a large proportion of NPS-S customers are women, at about 82.2 percent.

Thus, the characteristics of the KGFS pensions customers appear contrary to the earlier studies that predict that individuals and households that are lower on the income or socio-economic scale are less likely to participate in a voluntary, defined contribution pension scheme. One reason could be that low-income households typically find it difficult to access formal finance making NPS-S one of the only schemes available to build a retirement corpus outside of traditional and informal modes of saving. A matched contribution of Rs.1000 may also be valued more by low-income households.

We analyse persistence by dividing the sample into three categories as follows: the first, Category I, consists of those households who have contributed more than Rs.1000 in each financial year since enrollment. The second, Category II, consists of households that have managed to contribute Rs.1000 at least once since enrollment, but have not managed to do it for all the years. The third, Category III, has households who have not contributed Rs.1000 or more in any financial year since enrollment.

An observation from the characterizations of the three Categories in Table 3 is that Category III has the lowest proportion of women. Except for gender however, there is no characteristic that is consistently different across the three groups. For example, while the third group reports the lowest per 
Table 4 Persistence by year of enrollment

This table presents the percentage of households by year of enrollment that had contributed more than Rs.1000 in each financial year. The numbers are percentages, unless stated otherwise. For example, of the 6087 individuals that enrolled in the financial year 201011, 27 percent had contributed more than Rs.1000 in 2010-11, 33 percent in 2011-12 and 35 percent in $2012-13$.

\begin{tabular}{lrrrr} 
Financial & \multicolumn{4}{c}{ Year of enrollment } \\
Year & Number & $2010-11$ & $2011-12$ & $2012-13$ \\
\hline 2011 & 6087 & 26.8 & 32.7 & 34.8 \\
2012 & 16972 & 0.0 & 21.6 & 37.6 \\
2013 & 14510 & 0.0 & 0.0 & 53.5 \\
\hline
\end{tabular}

capita household income, the middle group has lowest proportion of households with private sanitation. They, however, have the highest proportion of home-ownership and electricity connection. The summary statistics do not reveal any obvious characteristics that differentiate households that persist in their contributions compared to those that have never reached the Rs.1000 threshold even once.

\subsection{Dynamics of NPS-S participation}

Figure 3 shows the time-series of enrollments and aggregate contributions respectively. The surge in participation in the months of January to March 2011 can probably be attributed to the initial enthusiasm around the scheme.

Contribution flows, on the other hand, do peak around the end of each financial year, most likely a result of the deadline for the matched contribution. While there were relatively few enrollments in the early part of 2012, contributions from the existing pool of members continues to rise. In fact, the contributions flow in 2013 has improved relative to the previous two years. By the end of 2013, the scheme had greater contributions from its members.

The remuneration of intermediaries by the PFRDA was doubled after April 2011 leading to greater incentives for aggregators (such as KGFS) to ensure that participants contributed at least Rs.1000 in a financial year. The change in persistence however is seen in the year 2012-13, when there was a decision by management to distribute the product with a focus on saving for the long term.

This is reinforced by Table 4 which shows the proportion of households that contributed greater than Rs.1000 by year of enrollment. While the number of enrollments were the highest in 2011-12 the persistence of the 2011-2012 
Figure 3 NPS-S enrollments and contribution flows.

The top panel in the figure reflects the time-series of enrollments into the NPS-S and the bottom panel shows the aggregate contributions into the NPS-S.
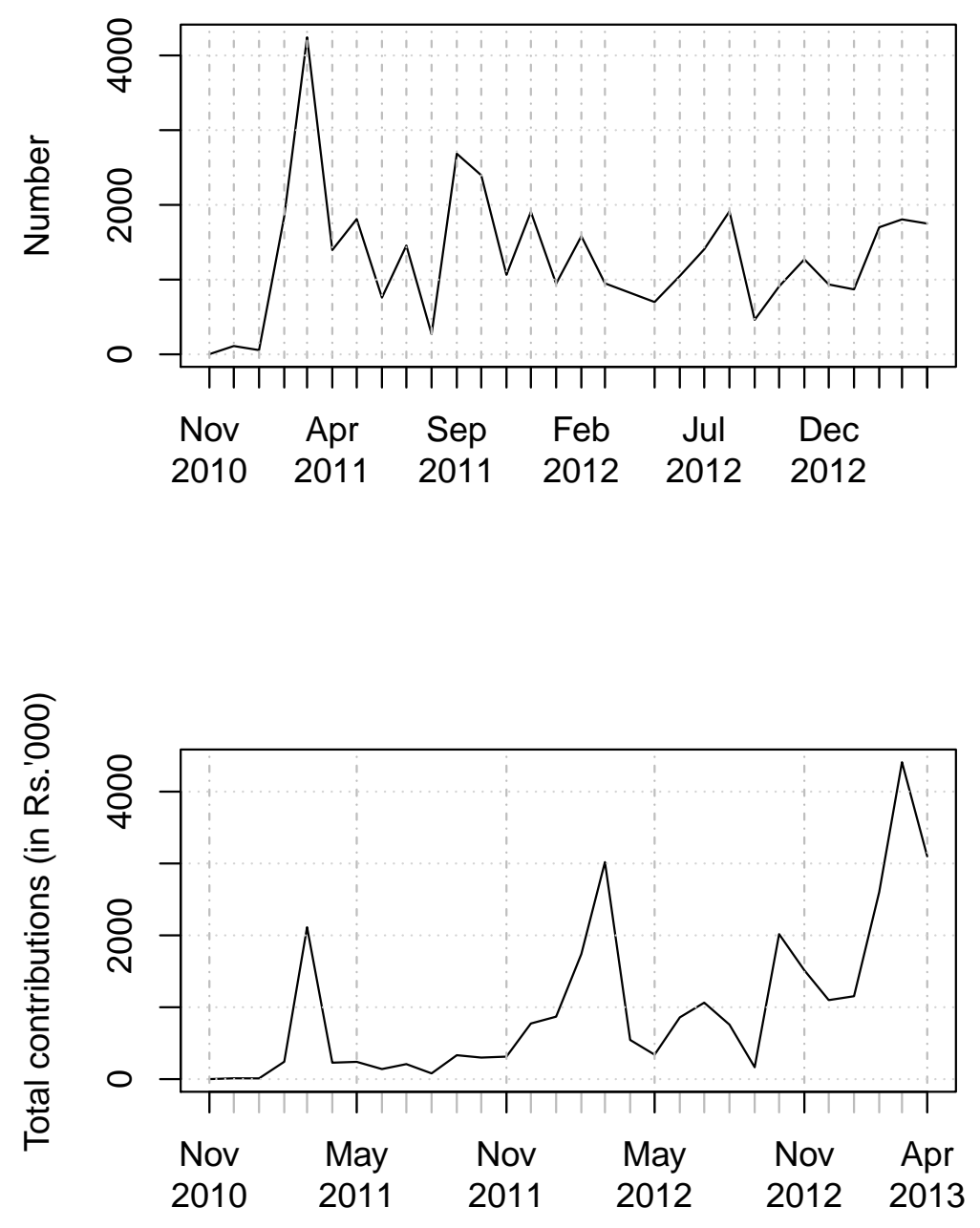
Table 5 Participation by year of enrollment

This table reflects the characteristics of participants by the year of enrollment. The numbers are percentages, unless stated otherwise.

\begin{tabular}{lrrr} 
& \multicolumn{3}{c}{ Year of enrollment } \\
& $2010-11$ & $2011-12$ & $2012-13$ \\
\hline Male & 24.2 & 15.9 & 17.3 \\
Own land & 33.8 & 38.0 & 36.0 \\
Own home & 82.3 & 88.5 & 84.0 \\
Have electricity & 85.9 & 89.0 & 83.9 \\
Private toilet & 21.5 & 17.7 & 20.0 \\
Cooking medium: Gas & 14.5 & 12.6 & 15.5 \\
Caste: Non OBC/SC/ST & 87.2 & 91.9 & 87.0 \\
Median household income (Rs.) & 24000.0 & 24000.0 & 25000.0 \\
Number of children & 2.0 & 2.0 & 2.0
\end{tabular}

participants was the lowest. The 2012-13 cohort shows a remarkable jump in persistence: 53 percent had contributed more than Rs.1000 in the financial year.

What is interesting is that participants persist in contributing even if they failed to contribute the minimum amount in a given year. For example, of those enrolled in 2012 and not able to contribute Rs.1000 in that year, 30.5 percent contributed Rs.1000 in 2013. This emphasizes that low contributions in one year, need not imply low contributions over the trajectory of the working life.

Table 5 presents the differences in characteristics of participants. This is useful to evaluate if this change was driven by selection of different households into the the NPS-S. If contributions improved in 2013, then a question that arises is if this was because of wealthier or more educated households selecting themselves into the NPS-S.

We find no statistically significant difference in the per capita household income of those who enrolled in 2012 and 2013. In fact, fewer households in 2013 owned land, and a family home relative to 2012. A greater proportion of the 2013 households claimed to have a private toilet relative to 2012 . The participant profile is thus mixed over the years. This suggests that distribution really matters, and the influence of education in improving persistence is at least equal, if not greater than financial incentives in isolation.

These descriptions serve to illustrate two features about the participation among the KGFS pensions customers. First, there is considerable interest in the idea of a pension product in the informal sector. Second, regular contributions required for a matched contribution by the government are limited, but improve over time. 


\section{Results}

\subsection{Participation decision}

Column (1) in Table6 6 presents the coefficients, or the log-odds, from the logit estimation and column (4) presents the marginal effects which reflect the probability of participation of a one-unit change in the continuous variables at the mean, and a shift in a dichotomous variable from zero to one.

\section{Hypothesis 1: Income}

The hypotheses discussed in Section 3 suggest that income should be positively correlated to persistence, while asset ownership should be negatively correlated. The relationship between income and participation is contrary to our expectations. Participation probability decreases with income, though not statistically significant.

The problems in accurate measurement of income require that we use several proxies for income such as variables that reflect the socio-economic status of households. For example, private sanitation and cooking gas are indicative of the relatively well-off households. Households with these facilities have on average, a higher per capita income than households without. We find that households without a private toilet and without cooking gas, i.e. the lowest socio-economic strata households are most likely to participate in the NPS-S. Those in the highest socio-economic strata, i.e. with a cooking gas and with a private toilet are least likely to participate. Similary, households with access to public health are the lower-income households, and are more likely to sign up to the NPS-S. These results suggests that is the relatively less well-to-do households that are opting to participate in the NPS-S.

\section{Hypothesis 2: Assets}

Land-owners are 0.4 percentages point less likely to participate than those who do not own land, significant at 1 percent. Those with homes, regardless of quality, are more likely to participate than those who do not own a home. It is difficult to interpret results on illiquid assets such as land and the family home. On the one hand, ownership of these assets, and their quality, may imply that households have wealth which can be a substitute for pension wealth. However, given the difficulty of drawing down these assets, their use for old-age consumption is limited.

Hypothesis 3: Children 
Table 6 Who participates?

This table presents the estimates of a logit regression on the probability of NPS-S participation. The base for the house type variable is a household who does not own a home. Low socio-economic status households are those without access to both gas (as cooking medium) and private toilet. Education reflects the highest education category of the family. The base for the education variable is the class 12 category. The base for the occupation variable is agriculture. The base for caste are the higher castes. The regression includes dummies for regions. The sample excludes individuals above the age of 75 and whose annual household income is less than Rs.5000, and greater than Rs.1 million.

\begin{tabular}{|c|c|c|c|c|c|c|}
\hline & $\begin{array}{r}(1) \\
\text { Estimate }\end{array}$ & $\begin{array}{r}(2) \\
\text { Std. error }\end{array}$ & $(3)$ & $\begin{array}{r}(4) \\
\text { Marginal } \\
\text { effect }\end{array}$ & $\begin{array}{r}(5) \\
\text { Std. error }\end{array}$ & (6) \\
\hline Intercept & -5.50 & 0.18 & $* * *$ & -0.36 & 0.01 & $* * *$ \\
\hline $\log ($ hh inc. per capita $)$ & -0.00 & 0.01 & & -0.00 & 0.00 & \\
\hline has land & -0.06 & 0.02 & $* * *$ & -0.00 & 0.00 & $* * *$ \\
\hline house type: high & 0.41 & 0.05 & $* * *$ & 0.03 & 0.00 & $* * *$ \\
\hline house type: medium & 0.26 & 0.06 & $* * *$ & 0.02 & 0.01 & $* * *$ \\
\hline house type: low & 0.48 & 0.05 & $* * *$ & 0.03 & 0.00 & $* * *$ \\
\hline number cons. durables & -0.02 & 0.00 & $* * *$ & -0.00 & 0.00 & $* * *$ \\
\hline number children & 0.03 & 0.01 & $* * *$ & 0.00 & 0.00 & $* * *$ \\
\hline cooking gas and toilet & -0.07 & 0.04 & $*$ & -0.01 & 0.00 & * \\
\hline no cooking gas-no toilet & 0.13 & 0.03 & $* * *$ & 0.01 & 0.00 & $* * *$ \\
\hline no cooking gas-toilet & -0.01 & 0.04 & & -0.00 & 0.00 & \\
\hline has electricity & 0.05 & 0.03 & $*$ & 0.00 & 0.00 & * \\
\hline access to public health care & 0.17 & 0.02 & $* * *$ & 0.01 & 0.00 & $* * *$ \\
\hline age & 0.22 & 0.01 & $* * *$ & 0.01 & 0.00 & $* * *$ \\
\hline age2 & -0.00 & 0.00 & $* * *$ & -0.00 & 0.00 & $* * *$ \\
\hline male & -1.71 & 0.02 & $* * *$ & -0.11 & 0.00 & $* * *$ \\
\hline single & -2.10 & 0.07 & $* * *$ & -0.14 & 0.00 & $* * *$ \\
\hline edu: graduate plus & -0.08 & 0.06 & & -0.01 & 0.00 & \\
\hline edu: illiterate & -0.06 & 0.02 & $* * *$ & -0.00 & 0.00 & $* * *$ \\
\hline occ: business & 0.41 & 0.03 & $* * *$ & 0.03 & 0.00 & $* * *$ \\
\hline occ: driver & 0.06 & 0.09 & & 0.00 & 0.01 & \\
\hline occ: house-wife & 0.24 & 0.03 & $* * *$ & 0.02 & 0.00 & $* * *$ \\
\hline occ: labourer & 0.11 & 0.02 & $* * *$ & 0.01 & 0.00 & $* * *$ \\
\hline occ: not working & -0.49 & 0.10 & $* * *$ & -0.03 & 0.00 & $* * *$ \\
\hline occ: rental income & 0.35 & 0.41 & & 0.03 & 0.04 & \\
\hline occ: regular income/professional & -0.26 & 0.05 & $* * *$ & -0.01 & 0.00 & $* * *$ \\
\hline religion: non-hindu & -0.18 & 0.04 & $* * *$ & -0.01 & 0.00 & $* * *$ \\
\hline caste: $\mathrm{SC} / \mathrm{ST} / \mathrm{OBC}$ & 0.05 & 0.03 & $*$ & 0.00 & 0.00 & * \\
\hline Log-likelihood & -58941 & & & & & \\
\hline Number of observations & 187447 & & & & & \\
\hline
\end{tabular}


One would expect that the larger the number of children, the lower the participation in the pension program. In our sample, one more child is associated with a 0.2 percentage points probability of participation. This result may be largely driven by the fact that the number of children is uniform across households 14

\section{Other demographic controls}

The difference between the participation rates of men and women is strongly confirmed by the estimation as men are significantly less likely to participate than women in the NPS-S. The results are also generally consistent with international evidence on pension contributions in terms of age and marital status. For example, age is positively associated with participation, and married individuals are more likely to participate. ${ }^{15}$ Graduates and illiterate are less likely to participate than those with a schooling degree. What these results show is that these similar characteristics hold for a very different set of individuals, in a voluntary system, where there is no employer, and no state provided social-security.

The estimated coefficients on the occupation variables reflects the eligibility conditions of the scheme which applies only to those not covered by occupational plans ${ }^{16}$ Thus, an occupation with regular income is negatively correlated, since those with regular wages are more likely to be covered by the formal pension scheme already. Those out of a job are also less likely to participate in the NPS-S, which is consistent with the notion that savings requires a source of income.

The differential relationship between participation and income, and participation and socio-economic characteristics such as education and better sanitation reflect that in a population where old-age income security is a purely private problem, those that are relatively less well-off do choose to participate. These are individuals with limited access to formal finance, and their participation is encouraging for public policy that seeks to promote voluntary contributions by creating institutions that explicitly seek to broaden financial access.

\footnotetext{
${ }^{14} \mathrm{~A}$ central part of the hypothesis was the impact of the number of male children on participation. The gender of the child has not been recorded for a large number of cases. We therefore present results without this variable. The variable appears insignificant when included. Results are available on request.

${ }^{15}$ See (Munnell, Sunden, and Taylor, 2002; Munnell et. al., 2009)

${ }^{16}$ Occupational pensions in India include a provident fund and pension scheme run by the Employees Provident Fund of India. These schemes are applicable only to those employees who work in establishments with 20 or more employees.
} 


\subsection{Contributions persistence}

Table 7 presents the results on the analysis of persistence of contributions based on three measures of persistence: $\log$ (total contributions) (columns (1) and (2)), probability of contributing upto the Rs.1000 threshold in each year since participation (columns (3) and (4)), and the probability of making a second contribution (columns (7) and (8)).

\section{Hypothesis 1, 2: Income and assets}

Total contributions are increasing in income with an estimated coefficient that is positive and significant at the one percent level. Households with a higher per capita income also have a higher probability of contributing Rs.1000 significant at the 1 percent level. The positive correlation should mean that as the growth rate of income increases, so will the pension contributions.

Households with private sanitation and cooking gas, show high persistence according to all three measures. The less well-off households i.e. those without sanitation and cooking gas are able to contribute a second time. However, their probability of contributing Rs.1000 is not statistically different from zero. Access to public health is negative correlated with the probability of a Rs.1000 contribution and the probability of a second contribution. These are consistent with the result on income which shows that the relatively less well-off households are less likely to persist in making contributions.

The probability of Rs.1000 contributions is however, decreasing in landownership. Home-owners, with the highest quality of the family home have higher total contributions relative to those with the lowest quality homes. There is no significant relationship between number of consumer durables and persistence. The evidence on assets is therefore mixed.

\section{Hypothesis 4: First contribution amount}

We had expected the first contribution amount to not make a difference to persistence. The results, however, point out that the greater the first contribution amount, the greater is the total contribution of the member, the greater is the probability of the Rs.1000 contribution, and the lower is the probability of a second contribution. This implies that those who are able to contribute a large amount in one transaction are the ones with better persistence. There is thus limited evidence of the use of the multiple small valued transactions strategy, at least for a minimum transaction size of Rs.100. 


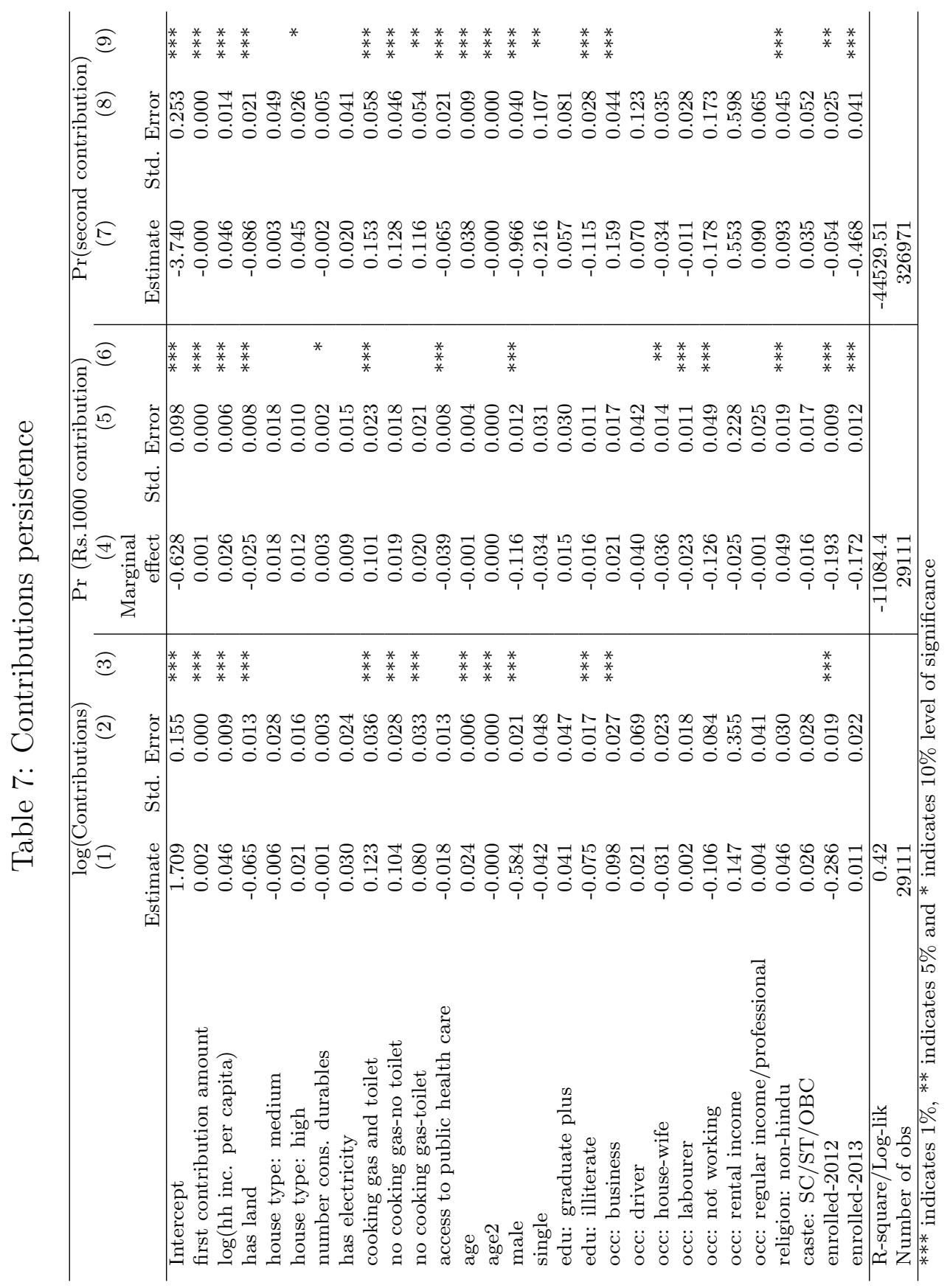




\section{Other controls}

Demographic variables such as age, and gender continue to stay consistent with the participation results. Men are less likely than women to fare well on persistence measures, as are single households. Households in the illiterate category have the lowest total contributions and the lowest probability of making a second contribution. Education is often related to better outcomes on the labor market, and low education is also likely to reflect low financial literacy. Both these may influence the likelihood of illiterate households to not contribute to their pension account.

The results on both participation and persistence point out that households with lower income and socio-economic characteristics find the idea of a pension account attractive. There is thus considerable interest about a pension plan among lower-income households. These households are not necessarily able to contribute Rs.1000 every year. Once enrolled, it is the relatively well-off households who are able to put aside Rs.1000 and enjoy the benefit of the governments contribution to their pension accounts. The results also point out that distribution matters, and has an important role to play in improving persistence.

\section{Conclusion}

The NPS-S in India is an important experiment in the pension system reforms process. The program invites voluntary participation of a heterogeneous, informal sector, into a defined contribution (DC) scheme, which is run using the infrastructure of modern pension fund management. It is implemented through a network of non-governmental organizations that conduct marketing and enrollment functions by utilizing existing networks and credibility in their area of operation. In order to incentivise potential participants to save for old age, the Indian government has offered a modest matched defined contribution of Rs.1000 for the first ten years of participation in the program.

The international evidence about long-term savings participation presents a gloomy picture about the success of such a voluntary, defined contribution pension system. Illiquidity of the product, uncertainty about interest rates and the annuitization requirement probably should have led to near-zero participation rates.

A more optimistic picture emerges from an analysis of the NPS-S partici- 
pation of customers of the NPS-S obtained from a financial services firm, Kshetriya Grameen Financial Services (KGFS) in India. Despite the fairly modest scale of a matching contribution from the government, a significant number of customers participate in the NPS-S. Participation seems to be negatively correlated with asset ownership, but positively correlated with income and other socio-economic characteristics such as private sanitation and caste. The evidence presented in this paper shows that voluntary participation in an individual account DC pension system is feasible.

The key revealation lies in the persistence of contributions by the KGFS NPS-S participants. About 50 percent of the customers who have signed up for the NPS-S do not manage to contribute the required Rs.1000 over 12 months. However, several of them continue to contribute to the scheme over subsequent years. In this paper, we have documented some characteristics about these individuals. They are less likely to own land, and have low income, and start with a low-valued contribution. This suggests that the KGFS NPS-S participants are those who have less access to formal finance. It is also important to note that for several households, the NPS-S is their first foray into formal finance. The participation and persistence, limited as it may seem at present, could be the beginning of more systematic and regular contributions towards a pension account.

Even though the persistence behaviour may be disappointing evidence about the use of the MDC as a policy tools to incentivise pensions system participation, the potential for a pension system for informal sector workers is more optimistic. If 50 percent of those who signed up in one financial firm can begin accumulating pension wealth at the first implementation of the scheme, it translates to a large number of people when extrapolated to the scale of a country the size of India.

The study raises pertinent questions on whether the government should continue the subsidy and in what form. For example, the government may choose to dismantle the minimum threshold of Rs.1000 and provide an equal match upto a ceiling, enabling more individuals to benefit from the subsidy. Alternatively, the government may limit the scheme to households who can contribute the minimum amount (of Rs.1000) every year, at least till such time technology can drive down transactions costs and make even lower-valued transactions (i.e. less than Rs.100) viable. The costs and benefits of either option need to be considered as a successful implementation has tremendous implications for pension system design and financial intermediation.

Finally, our findings open up promising avenues for future research. These primarily relate to the reasons for non-participation, and low persistence. 
Questions such as the importance of credit and insurance availability to deal with economic or other shocks, and behavioural aids such as reminders, financial literacy programs, pre-commitment schemes among others require variation in the form of natural and randomised control experiments for identification. We hope that this paper sets the stage for the development of a promising research agenda on voluntary pension systems for low-income workers. 


\section{References}

Agnew et. al (2012): "Trust, plan knowledge and 401(k) savings behavior," Journal of Pension Economics and Finance, 11(1), 1-20.

Allison, P. (1982): "Discrete time methods for the analysis of event histories," in Sociological Methodology, ed. by S. Leinhardt. Jossey-Bass, San Francisco.

Ananth, Bindu, Gregory Chen, and Stephen Rasmussen (2012): "The pursuit of complete financial inclusion: The KGFS model in India," Access to Finance Forum, Reports by CGAP and its Partners 4, CGAP and IFMR Trust.

Angelini, Viola (2007): "The strategic bequest motive: Evidence from SHARE," Macro Fanno Working Paper 62, Dipartimento di Scienze Economiche, Universita di Padova.

Angelini et. al. (2012): "The Dynamics of Homeownership among the 50+ in Europe," Working Paper DP8889, Centre for Economic Policy Research.

Bassett, William F., Michael J. Fleming, and Anthony P. Rodrigues (1998): "How Workers Use 401(k) Plans: The Participation, Contribution, and Withdrawal Decisions," National Tax Journal, 51(2), 263-290.

Bernheim, Douglas, and Daniel Garrett (1996): "The determinants and consequences of financial education in the workplace: Evidence from a survey of households," Working Paper 5667, NBER.

Beverly, Sondra G., and Michael Sherraden (1999): "Institutional determinants of saving: implications for low-income households and public policy," Journal of Socio-Economics, 28, 457-473.

Carpena et. al. (2011): "Unpacking the Causal Chain of Financial Literacy," Policy Research Working Paper 5798, The World Bank.

Choi, James, David Laibson, and Brigitte Madrian (2004): "Plan design and 401(k) savings outcomes," National Tax Journal, 57(2), 275-298.

Cole et. al. (2012): "Barriers to household risk management: Evidence from India," Working Paper WP/12/195, IMF.

Dave, Surendra A. (2006): "India's Pension Reform: A Case Study in Complex Institutional Change," in Documenting Reforms: Case Studies From India, ed. by S. Narayan. Macmillan India and Observer Research Foundation. 
Dupas, Pascaline, and Jonathan Robinson (2012): "Why Don't the Poor Save More? Evidence from Health Savings Experiments," CEGA Working Paper WPS-010, The Center for Effective Global Action, UC Berkeley.

Dynan et. al. (2004): "Do the rich save more?," Journal of Political Economy, $111(2), 397-444$

Ebenstein, Avraham, and Steven Leung (2010): "Son Preference and Access to Social Insurance: Evidence from China's Rural Pension Program," Population and Development Review, 36(1), 47-70.

Engelhardt, Gary V., and Anil Kumar (2007): "Employer matching and 401(k) saving: Evidence from the health and retirement study," Journal of Public Economics, 91(10), 1920-1943.

Giné, Xavier, Robert Townsend, and James Vickery (2008): "Patterns of rainfall insurance participation in rural India," World Bank Economic Review, 22(3), 539-66.

Guariglia, Alessandra, and Sheri Markose (2000): "Voluntary contributions to personal pension plans: Evidence from the British Household Panel Survey," Fiscal Studies, 21(4), 469-488.

Guiso, Luigi, Paola Sapienza, and Luigi Zingales (2008): "Trusting the stock market," Journal of Finance, 63(6), 2557-2600.

Holzmann, Robert, Truman Packard, and Jose Cuesta (2000): "Extending coverage in multi-pillar systems: Constraints and hypothesis, preliminary evidence and future research agenda," in New Ideas About Old Age Security, ed. by R. Holzmann, and J. Stiglitz. The World Bank.

$\mathrm{Hu}, \mathrm{Yu}-$ Wei, and Fiona Stewart (2009): "Pension Coverage and Informal Sector Workers," Working Papers on Insurance and Private Pensions 31, OECD, doi:10.1787/227432837078.

Hubbard, R. Glenn, Jonathan Skinner, and Stephen P. Zeldes (1994): "Expanding the Life-Cycle model: Precautionary Saving and Public Policy," The American Economic Review, 84(2), 174-179, Papers and proceedings of the Hundred and Sixth Annual Meeting of the American Economic Association.

Huberman, Gur, Sheena S. Iyengar, and Wei Jiang (2007): "Defined Contribution Pension Plans: Determinants of Participation and Contributions Rates," Journal of Financial Services Research, 31(1), 1-32. 
IIMS Dataworks (2008): "The Sleeping Giant: Private pension markets in India," An IIMS Dataworks Research Project.

ILO (2010): "World Social Security Report 2010/11: Providing Coverage in Times of Crisis and Beyond," Discussion paper, International Labour Organisation.

Lusardi, Annamaria, and Olivia S. Mitchell (2007): "Financial Literacy and Retirement Preparedness: Evidence and Implications for Financial Education Programs," Working Paper 2007/15, Center for Financial Studies (CFS).

MacKellar, Landis (2009): "Pension Systems for the Informal Sector in Asia," SP Discussion Paper 0903, The World Bank.

Madrian, Brigitte C. (2012): "Matching contributions and savings outcomes: A behavioral economics perspective," Working Paper 18220, NBER.

Munnell, Alicia H., Annika Sunden, and Catherine Taylor (2002): "What Determines 401(k) Participation and Contributions," Social Security Bulletin, 64(3), 64-75.

Munnell et. al. (2009): "An update on 401(k) plans: Insights from the 2007 survey of consumer finance.," Working Paper 2009-26, Center for Retirement Research, Boston College.

Palacios, Robert, and David A. Robalino (2009): "Matching Defined Contributions: A Way to Increase Pension Coverage," in Closing the Coverage Gap: The Role of Social Pensions and Other Retirement Transfers, ed. by R. Holzmann, D. A. Robalino, and N. Takayama. The World Bank.

Palacios, Robert, and Renuka Sane (2013): "Learning from the early experience of India's matching defined contribution scheme," in Matching Contributions for Pensions: A Review of International Experience, ed. by H. et. al. The World Bank.

Papke, Leslie E. (1995): "Participation in and contributions to 401(k) plans: Evidence from Plan Data," Journal of Human Resources, 30(2), 311-325.

Poterba et. al. (2011): "The composition and drawdown of wealth in retirement," Journal of Economic Perspectives, 25(4), 95-118.

Saez, Emmanuel (2009): "Details Matter: The Impact of Presentation and Information on the Take-Up of Financial Incentives for Retirement Saving," American Economic Journal: Economic Policy, 1(1), 204-28. 
Sane, Renuka, and Ajay Shah (2011): "Civil service and military pensions in India," in Reforming Pensions for Civil and Military Servants, ed. by N. Takayama. Maruzen Publishing.

Shah, Ajay (2006): "Indian pension reform: A sustainable and scalable approach," in Managing globalisation: Lessons from China and India, ed. by D. A. Kelly, R. S. Rajan, and G. H. L. Goh. World Scientific. 